\title{
Treatment of cotton with an alkaline Bacillus spp cellulase: Activity towards crystalline cellulose
}

\author{
Cristina Caparrós ${ }^{7}$, Carmen López ${ }^{1}$, Marc Torre $\|^{2}$, Neil Lant ${ }^{3}$, Johan Smets ${ }^{4}$ and Artur Cavaco-Paulo ${ }^{1}$ \\ ${ }^{1}$ Department of Textile Engineering, Minho University, Guimarães, Portugal \\ ${ }^{2}$ Centro de Física, Minho University, Guimarães, Portugal \\ ${ }^{3}$ Procter \& Gamble, Newcastle Upon Tyne, UK \\ ${ }^{4}$ Procter \& Gamble, Brussels Innovation Centre, Strombeek-Bever, Belgium
}

\begin{abstract}
We analysed the influence of several enzymatic treatment processes using an alkaline cellulase enzyme from Bacillus spp. on the sorption properties of cotton fabrics. Although cellulases are commonly applied in detergent formulations due to their anti-redeposition and depilling benefits, determining the mechanism of action of alkaline cellulases on cotton fibres requires a deeper understanding of the morphology and structure of cotton fibres in terms of fibre cleaning. The accessibility of cellulose fibres was studied by evaluating the iodine sorption value and by fluorescent-labelled enzyme microscopy; the surface morphology of fabrics was analysed by scanning microscopy. The action of enzyme hydrolysis over short time periods can produce fibrillation on cotton fibre surface without any release of cellulosic material. The results indicate that several short consecutive treatments were more effective in increasing the fibre accessibility than one long treatment. In addition, no detectable hydrolytic activity, in terms of reducing sugar production, was found.
\end{abstract}

$\begin{array}{ll}\text { Received } & 15 \text { October } 2010 \\ \text { Revised } & 21 \text { July } 2011 \\ \text { Accepted } & 22 \text { September } 2011 \\ \text { Accepted } & \\ \text { article online } & 26 \text { September } 2011\end{array}$

Keywords: Alkaline cellulase $\cdot$ Cellulose fibres $\cdot$ Cotton $\cdot$ Microfibrils

\section{Introduction}

The detergent industry has been using enzyme technologies in detergent formulations for the last 30 years. Enzymatic hydrolysis in detergency is usually focused on the fragmentation of the soil or stains into smaller particles, which are then more accessible to the chemical ingredients of the detergent formulation [1-3]. Today, enzymes are commonly used in many industrial applications and $75 \%$ of the industrial enzymes are hydrolases, of which carbohydrolases represent the second largest group [4-7]. Recently, the use of novel en-

Correspondence: Dr. Artur Cavaco-Paulo, Department of Textile Engineering, Minho University, Azurem, 4800058 Guimarães, Portugal E-mail: artur@det.uminho.pt

Abbreviations: ISV, iodine sorption value; $\Delta \mathrm{ISV}$, differential ISV; SEM, scanning electron microscopy zymes that are claimed to effect textile substrate modifications have been reported, and it has been assumed that these represent advances for textile industries $[8,9]$.

Cellulases comprise a group of different acting enzymes that, in coordinated action, degrade cellulose and their derivatives to glucose (endoglucanase, exoglucanase or $\beta$-glucosidase) [10-18]. The complex interactions among endoglucanase [19], cellobiohydrolase and $\beta$-1,4-glucosidase change substrate characteristics during the hydrolysis and these changes are represented in Fig. 1. As can be seen from the figure and the bibliography, endoglucanases cut at random amorphous sites of the cellulose chain, producing oligosaccharides of various lengths and new reducing and non-reducing ends on the fibre surface. During the cellulose hydrolysis, the solid substrate characteristics vary, with the number chain ends changing due to the action of endoglucanase and exoglucanase. This alters the cellulose accessibility as a result of sub- 


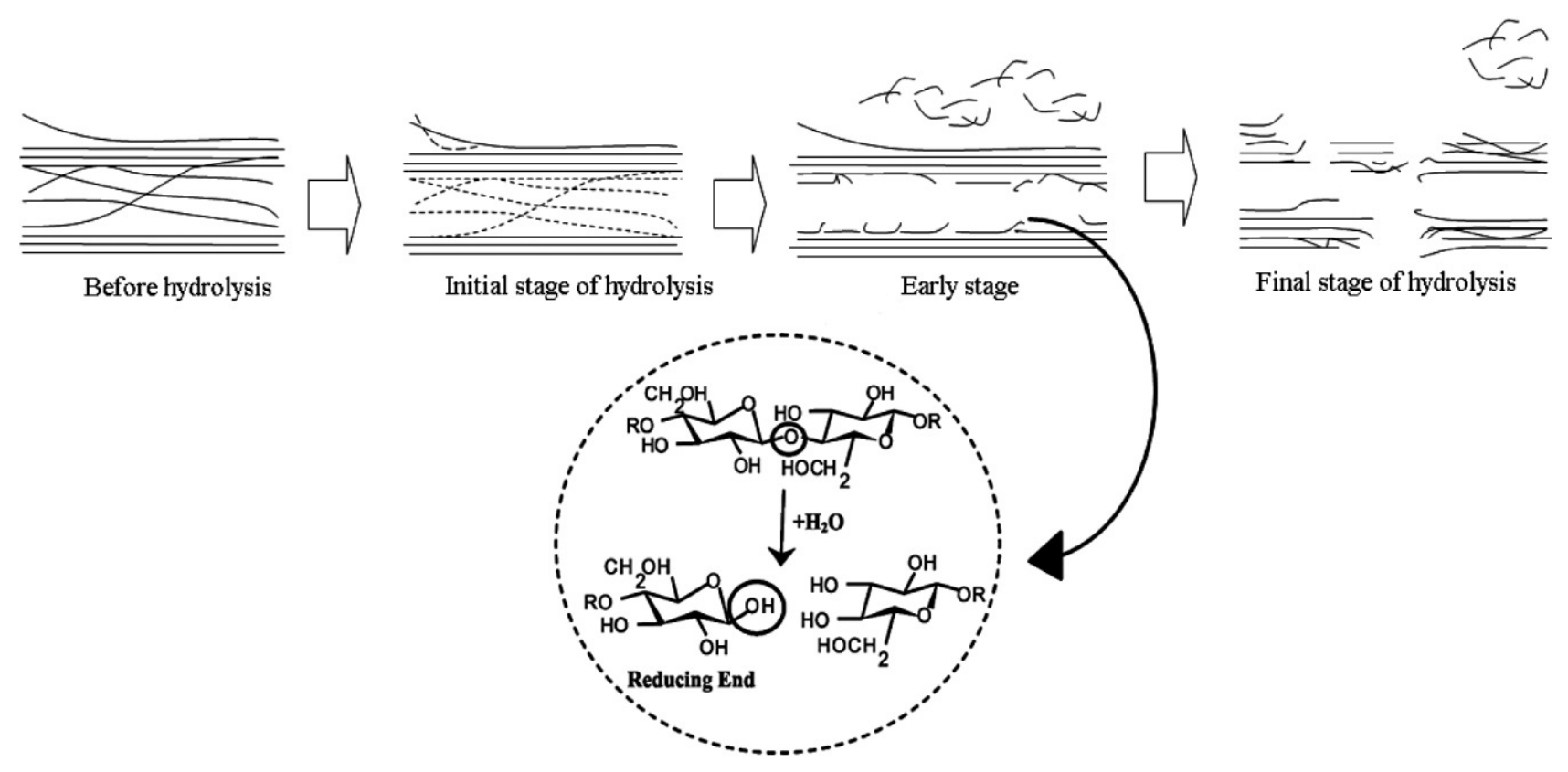

Figure 1. Main stages for degradation of cotton fibres by cellulase are presented. Endoglucanases cut at random amorphous sites of the cellulose.

strate consumption and cellulose fragmentation [20-24].

In detergency, cellulase action should be confined to the first stages of hydrolysis to avoid modification of fabric structure, and the cellulose characteristics need to be verified. Two types of advantages can be identified: (i) dirt anti-redeposition benefits, as the partial interaction with single cellulosic chains permits an easy release of the trapped soil, and (ii) biopolishing or depilling effect, which will create colour revival and softening effects on the fabric. The colour revival and antipilling effect produced by cellulase action are indispensable benefits and cannot be easily achieved in detergency by other detergent ingredients. This effect can also be considered as an indicator for the care and protection of textiles [12,14]. A proposed mechanism for the release of dirt particles from cotton fibres is shown in Fig. 2. In general, dirt usually adheres to the damaged cotton and endoglu- canases hydrolyse the cellulose chains at random amorphous sites. As a result, the fibres become more accessible by chemical ingredients of the detergent formulation.

It has been known for a long time that alkalophilic Bacillus species are producers of alkalophilic cellulases, which show $\mathrm{pH}$ optima in the neutral to alkaline range. Cellulases from Bacillus species generally show good compatibility with subtilisin proteases, the use of which is interesting for detergent applications. These monocomponent cellulases present reduced anti-pilling properties [17]. The first bacterial alkaline cellulase was produced by Kao and it exhibited endo- $\beta$-1,4-glucanase activity (EC 3.2.1.4). The term „alkaline endoglucanase“ indicates an endoglucanase with an optimum $\mathrm{pH}$ above 7 and retaining more than $70 \%$ of its optimal activity at pH 10 [25]. These types of enzymes have been advertised as having excellent detergent effects, as shown on sebum-stained cot-
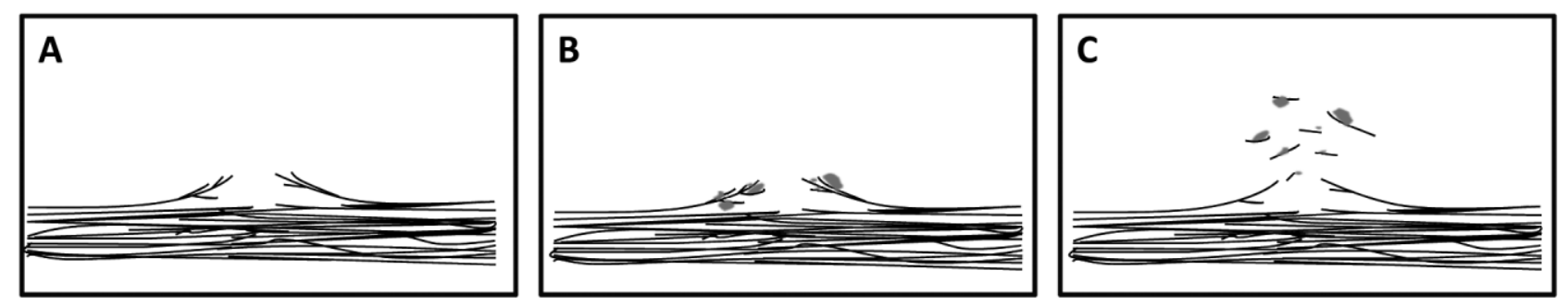

Figure 2. General mechanism for release of dirt particles from cotton fibres. (A) Damaged cotton fibres. (B) Dirt adheres to the damaged fibres. (C) Cellulases act on the damaged cellulose microfibrils, by hydrolyzing and suspending them in water. Adapted from Husum and Friis-Jensen [28]. 
ton [26]. Alkaline cellulases contribute indirectly to the removal of soil trapped in the amorphous region of cotton fibres by its reaction with cellulose molecule in the region. Murata et al. [14] proposed a mechanism based on the binding of water, which only occurred at hydroxyl groups of cellulose molecules in the amorphous region of cotton fibres. In fact, it was verified that soil entering the interfibre space of amorphous cellulose in the interior of cotton fibres, was slightly hydrolyzed and removed by alkaline cellulase. In addition, these cellulases cause no damage to the cotton fibre, solving problems relating to tensile strength loss after multiple wash cycles [15, 17, 27-30]. In addition, cellulases were shown to contribute to the whiteness of cotton-containing textiles after several washes [31].

In this work, the alkaline endoglucanase BaCel5 was used, which was commercialized as a preparation developed by Novozyme (Bagvaerd, Denmark) and called Celluclean ${ }^{\circledR}$. BaCel5 contains a cellulose-binding module (CBM) consisting of two tandem CBMs, one family 17 CBM and one family 28 CBM, both classified as B CBMs, which is supposed to be highly selective regarding amorphous cellulose and to have glucan-binding properties [32,33].

The main focus of this research was to study the detergency performance of cellulases when several wash cycles of cotton textiles were applied. Cotton garments treated by multiple washings with BaCel5 were characterised in terms of the modification of the accessibility of cotton fibre using iodine sorption value (ISV) tests, reducing-end production on the surface fibre and the interaction between the enzyme and the cellulose fibre using FITC-labelled enzyme. Scanning electron microscopy (SEM) was used to verify the fibre surface morphology.

\section{Materials and methods}

\subsection{Enzyme and fabrics}

The glycoside hydrolase nomenclature suggested by Henrissat and colleagues [11] has been adopted in this study, where Bacillus spp. cellulases are represented with the prefix $\mathrm{Ba}$. BaCel5 (cellulase type 5; EC 3.2.1.4) was supplied by Novozymes (Bagsvaerd, Denmark), under the trademark of Celluclean $^{\circledR}$, with activity of $325.4 \mathrm{EGU} / \mathrm{g}$.

Unbleached cotton woven fabrics (24/21 ends/ picks per $\mathrm{cm}$ and area density of $140 \mathrm{~g} / \mathrm{m}^{2}$ ) were used as the cellulosic substrate for the enzymatic treatments. Unbleached cotton was selected to avoid interferences in the fluorescence assays.
The proteins bovine serum albumin (BSA), glucose and fluorescein isothiocyanate (FITC) were obtained from Sigma. All other reagents used were of analytical grade.

\subsection{Enzymatic treatments}

Cotton fabrics ( $4 \mathrm{~g}$ ) were treated with BaCel5 cellulase with an enzymatic dosage of 1 and $0.5 \mathrm{mg}$ protein/L, in $800 \mathrm{~mL}$ of a model detergent at a 1:200 fabric to liquor ratio, at $40^{\circ} \mathrm{C}$. These studies were performed in a Detergent Tester (Copley Scientific, Nottingham, UK) with orbital agitation of $120 \mathrm{rpm}$. Two different treatments were performed: one single treatment of about 80 min and four consecutive treatments about 20 min each, adding new enzyme at the beginning of each treatment. Control samples were incubated in the same solution without enzyme and samples were removed after each incubation period. The cotton samples were analysed using an iodine adsorption test and an assay was also performed with FITC-labelled BaCel5. Since these series of experiments were designed to highlight the effect of repeated washing cycles when an alkaline cellulase was used, treatments using several washes were compared to the long singlewash treatments to evaluate the effect on cotton fibre surface of repeated washing using normal household conditions such as temperature, time and protein concentration. BaCel5 is believed to be stable for the whole 80-min washing cycle since sixfold more cellobiose is produced by a 120-min compared with a 20-min treatment under comparable conditions (our unpublished observations).

Additional repeated treatments were performed using the conditions previously described (enzymatic dosage, liquor ratio, agitation and temperature) to characterise the cotton surface. Some samples were treated in ten consecutive cycles of about $20 \mathrm{~min}$ each, others for $200 \mathrm{~min}$ and, finally, some for $48 \mathrm{~h}$. The cotton samples were analysed using reducing-end measurements and SEM.

It is important to note that, for all repeated treatments performed, new enzyme solution was added for each treatment. After enzymatic treatment, all samples were washed with deionised water for three 15-min cycles of at room temperature and, finally, air dried.

BaCel5 protein $(2 \mathrm{~mL}, 0.2 \mathrm{~g} / \mathrm{mL}$ in a sodium carbonate buffer, pH 9.0) was incubated with $100 \mu \mathrm{L}$ of FITC solution $(1 \mathrm{~g} / \mathrm{L})$ at room temperature for $2 \mathrm{~h}$. Unlinked FITC was separated by dialysis until no more FITC was released. Cotton samples were treated in this solution at $40^{\circ} \mathrm{C}$, at $125 \mathrm{rpm}$, for four repeated 20 -min treatments and a long treatment of $80 \mathrm{~min}$. The cotton samples were embedded in an 
epoxy resin and transvere $15-\mu \mathrm{m}$ cuts of the fibres were prepared using a microtome (Leitz). Cotton fibre cross-sections were analysed by a fluorescence microscope (Leica DM 5000B) at a magnification of $100 \times$ and $40 \times$.

\subsection{Physical analysis}

The accessibility of cotton fabrics after cellulase multitreatment was measured using an ISV assay. Cellulose fabric $(0.3 \mathrm{~g})$ was added to $1.2 \mathrm{~mL}$ iodinereactive solution (containing $5 \mathrm{~g}$ iodine and $40 \mathrm{~g}$ potassium iodide in $50 \mathrm{~mL}$ of water). Subsequently, $100 \mathrm{~mL} 200 \mathrm{~g} / \mathrm{L}$ sodium sulphate was added and, following a 1 - $\mathrm{h}$ incubation in the dark, the mixture was filtered. The iodine remaining in solution was titrated with standard sodium thiosulphate (0.01 M). The ISV was calculated for each treated cotton sample (as mg adsorbed iodine/g cellulose), and the differential ISV ( $\triangle \mathrm{ISV})$ for each treated fabric was correlated to the respective ISV value from control fabrics [34, 35].

The number of reducing ends, or reducing power, of cotton fabric samples after enzymatic treatment was measured by the method described by Cavaco-Paulo and colleagues [36, 37], which depends on the complex formed between neocuproine (2,9-dimethyl-1,10-phenanthroline) and reducing groups in the fibre. For the measurement, $0.1 \mathrm{~g}$ sample was incubated with $2 \mathrm{~mL} 2 \%$ sodium carbonate and $5 \mathrm{~mL}$ reactive aqueous solution of neocuproine containing: $0.2 \mathrm{~g} / \mathrm{L}$ copper (II) sulphate pentahydrate and $0.4 \mathrm{~g} / \mathrm{L}$ neocuproine. The mixture was boiled for $5 \mathrm{~min}$ and cooled to room temperature. Three analyses were done for each fabric sample. Absorbance was measured at $465 \mathrm{~nm}$ in a Helios Gamma UV-Vis spectrophotometer (Thermo Scientific, Waltham, MA, USA). The concentration of reducing sugar $(\mathrm{g} / \mathrm{L})$ was determined against glucose standards.

The surface morphology of cotton fabrics before and after enzymatic degradation was observed in a JEOL 5310 SEM. The samples were previously sputter-coated with gold with an ion sputter JEOL JFC 1100 to increase their conductivity. Free surface micrographs were taken at various magnifications and their microstructures were studied.

\section{Results and discussion}

The benefits of alkaline cellulases in detergent compositions have already been studied $[13,25,26$, 38-40]. Hoshino et al. [12] studied the mechanism of release of trapped soils with the alkaline cellulase, without any significant liberation of hydroly- sis products. Several benefits for the textiles had been claimed from studies of their interaction with dyes and surfactants and colourimetric investigations after several washes using these alkaline cellulases. The release of hydrolysis products is a possible final step in the degradation process, but no significant release was detected for these alkaline cellulases.

Specific characterisation was also required to evaluate the reproducibility of the action of the enzyme on the fibre under the same detergency conditions and, for example, at lower enzyme concentrations. For this, the investigations of the sorption properties of cellulose were focused primarily on the study of the variation of cotton fibre accessibility (measuring $\Delta \mathrm{ISV}$ ) and the definition of enzyme action, by labelling the enzyme fluorescently (with FTIC), and comparing samples after different types of treatment. The fibre accessibility and the ability of cellulose fibres to adsorb low molecular weight compounds give valuable information about the resulting fine structure (crystalline and amorphous regions, microfibrillar structure and morphology) [35]. The actual surface area accessible to the enzyme molecules in the solution also includes the pores, cavities and spaces between microfibrils. Different studies have found that the relative digestibility of cellulosic substrates is directly proportional to their accessibility to enzyme molecules [41]. The accessibility of cotton fabrics after cellulase multitreatment was measured using the ISV test, as the incorporation of iodine provides important information about the assimilation of low molecular weight species into the cotton fibre. First, four consecutive treatments of about $20 \mathrm{~min}$ each and then one single treatment of about $80 \mathrm{~min}$ were performed. Low enzymatic concentrations, renewed for each repetitive treatment, were used to reproduce the enzymatic levels employed in laundry detergent applications. According to previous work on alkaline cellulases [25], the lack of significant release of reducing sugar from cellulosic fibres under certain conditions could indicate that the fabrics have not been damaged. Therefore, enzyme activity on the cotton fabrics was measured in terms of reducing-end production and fibre accessibility.

The ISV method involves quantifying the iodine adsorbed per gram of cotton. These values allow comparison of samples with morphological differences on the cotton fabric after wash treatments with BaCel5. Control samples undergoing the same treatment but without enzyme were prepared for each treated sample. $\Delta$ ISVs were calculated and these values led to the visualization of the differences in the accessibility of the fabric after treat- 


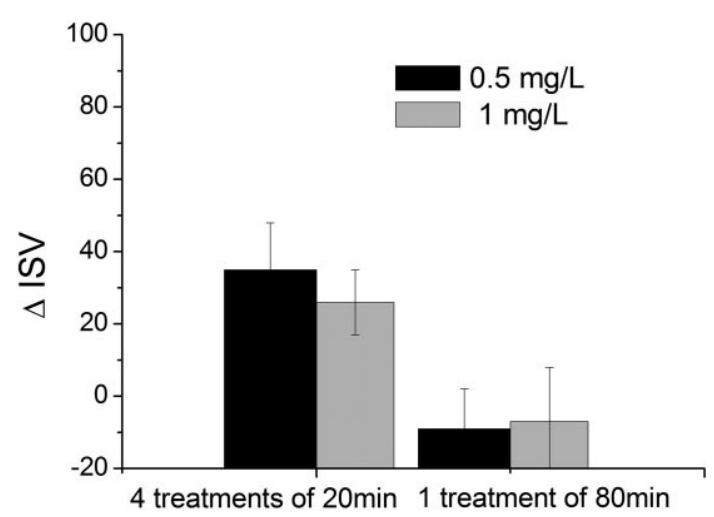

Figure 3. $\Delta I S V$ for indicated incubation periods. The ISV was calculated for each treated cotton sample (as $\mathrm{mg}$ adsorbed iodine/g cellulose), and $\Delta I S V$ values for each treated fabric was correlated with the respective ISV value from control fabrics. $\left(40^{\circ} \mathrm{C} ; 120 \mathrm{rpm}\right)$. Values represent the mean of three independent experiments and error bars the SD.

ment. A positive $\Delta \mathrm{ISV}$ is assumed to indicate an increase in the accessibility of cotton fabric; the higher ISV from the enzyme-treated fibres revealed an increased accessibility of amorphous areas. On the other hand, a negative $\Delta \mathrm{ISV}$ implies a decrease in accessibility [34, 35].

The results shown in Fig. 3 from treatments using high and low BaCel5 concentrations revealed that several short treatments led to an increase in accessibility on the fibre, and that no significant differences were seen with samples treated for $80 \mathrm{~min}$.

Samples from each successive treatment were collected to correlate each cycle with the final results (Fig. 3). As observed in Fig. 4, an increase in fabric accessibility was found from at least the second consecutive treatment, for both high and low BaCel5 concentrations. Comparing single treatments of $20 \mathrm{~min}$ and $80 \mathrm{~min}, \Delta \mathrm{ISV}$ results indicated that even at the shorter treatment times the enzyme produced an increase in the accessibility. When applying repeated treatments, BaCel5 was able to produce breaks in the cellulose across the fibre surface during a short hydrolysis period, acting as an endoglucanase. The results showed that the action of BaCel5 was enhanced over the repetitive treatments, but that this effect did not appear for a single long treatment. This effect can be observed by comparing single treatments of 20 and 80 min: a slight increase in $\triangle \mathrm{ISV}$ was observed as a consequence of the endoglucanase action, while these accessible amorphous areas created during the first 20 min of hydrolysis might be removed after the prolonged action in the 80-min treatment. However, the increase in the accessibility of the cotton fibre was proportional to the consequent washing steps, and can be assumed to be an accu-

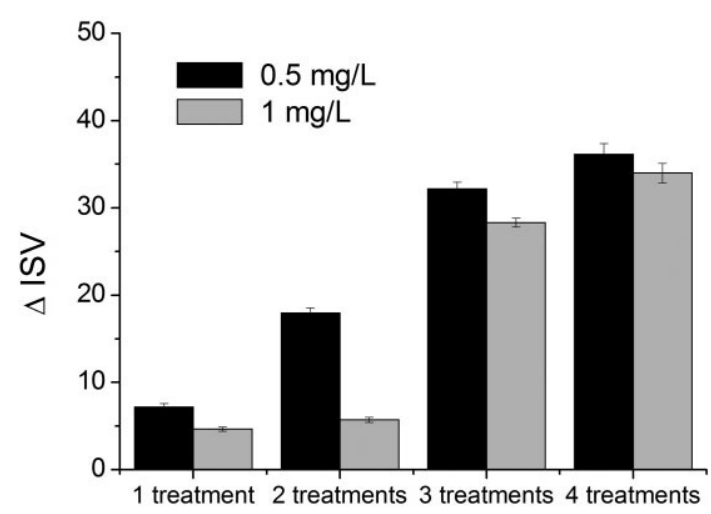

Figure 4. $\triangle \mathrm{ISV}$ of each treatment for indicated incubation periods. The ISV was calculated for each treated cotton sample (mg adsorbed iodine/g cellulose). The $\Delta \mathrm{ISV}$ values for each treated fabric were correlated with the respective ISV value from control fabrics. $\left(40^{\circ} \mathrm{C} ; 120 \mathrm{rpm}\right)$. Values represent the mean of three independent experiments and error bars the SD.

mulative effect produced by repetitive use of $\mathrm{Ba}$ Cel5.

The surface accessibility and interaction properties of cotton cellulose fibres are clearly modified by the different treatment processes (Figs. 3 and 4). In particular, these modifications cause a very distinct increase in the accessibility of low molecular weight compounds, such as water and iodine, especially after two repeated treatments of about 20 min.

The cross-section of a fibre in cotton after labelled enzyme treatment is shown in Fig. 5. After treating cotton fabrics with FITC-labelled enzyme, samples were examined by fluorescence microanalysis. Only traces of the residual fluorescence of the cotton itself were observed for the control sample, representing the initial state of the cotton fibre. In contrast, green-surrounded surfaces were detected on the surface of the cotton fabric for both treatments (four repeats of about $20 \mathrm{~min}$ and one of about $80 \mathrm{~min})$. When several short treatments were applied, a higher intensity around the fibre was achieved compared to long single treatment. Therefore, BaCel5 appears to acts on the fabric surface after several short treatments, rather than penetrating the fibre body. This fact is interpreted as a positive effect because it is generally accepted that enzymes must act on the fabric surface to avoid fabric damage. Cellulases should act on the fibre by causing fragmentation of cotton fibres. Shorter and weaker fibres are potentially easier to process by low enzymatic concentrations.

The fibre properties were also investigated by measuring reducing ends and by SEM. In these cases, treatments were modified by increasing the number and, consequently, the length of treatments: ten consecutive treatments of about $20 \mathrm{~min}$ 

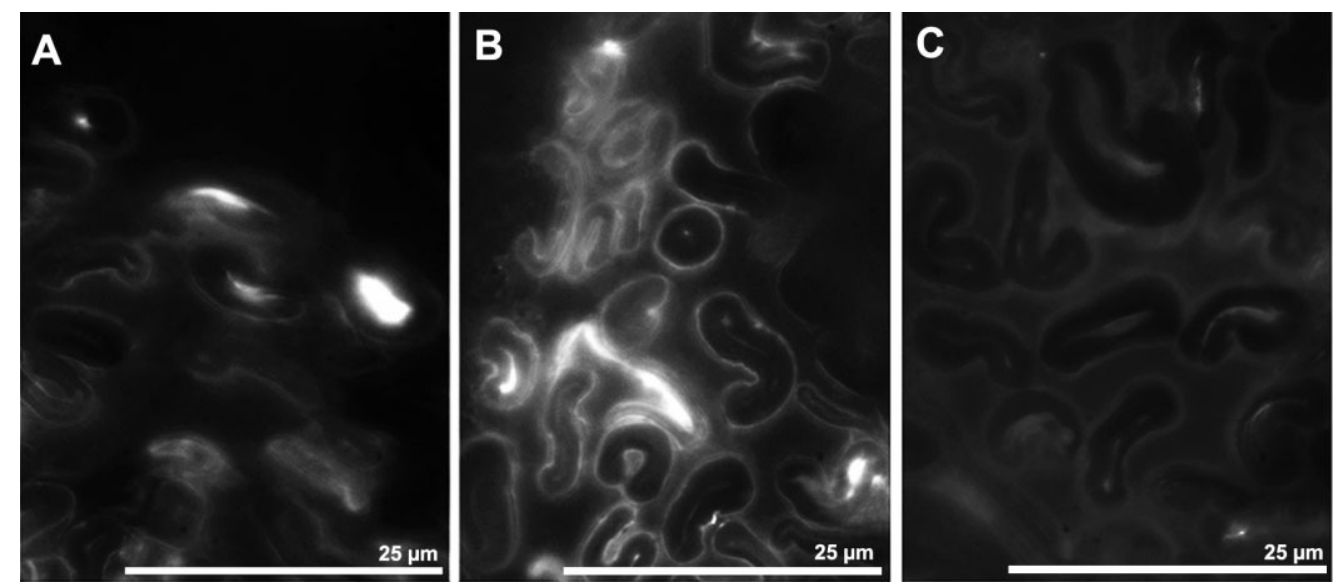

Figure 5. (A) Control samples, treated without enzyme. (1 mg protein $\left./ \mathrm{L} ; 40^{\circ} \mathrm{C} ; 125 \mathrm{rpm}\right)$. (B, C) Fluorescence microphotographs of fibre cross-sections of cotton treated with FITC-labelled BaCel5; (B) four treatments of about 20 min and (C) 80-min treatment.

were compared with one single treatment of about $200 \mathrm{~min}$, instead of four short repetitions and $80 \mathrm{~min}$. These modifications were performed to observe the effect of a higher number of washing cycles compared with a single cycle. The duration of the longer single treatment was chosen as $200 \mathrm{~min}$ to match that of the ten cycles of about 20 min to avoid the variable of the time. Low enzymatic concentrations were added at each repeat treatments and no reducing sugar production was found in the liquor treatment (data not shown).

Reducing ends on cotton were measured and SEM micrographs were evaluated to identify the effect on the fabric surface (Figs. 6 and 7). Cotton samples were subjected to ten consecutive treatments of about $20 \mathrm{~min}$, or one treatment for about $200 \mathrm{~min}$ or $48 \mathrm{~h}$ to attain measurable changes of cotton surface properties in terms of reducing ends on the cotton surface for longer treatment conditions.

These data indicated that samples treated several times with $\mathrm{BaCel} 5$ attain the highest value compared with samples treated for about $200 \mathrm{~min}$ or $48 \mathrm{~h}$. The repeated application of enzyme, by replenishing the enzymatic solutions, caused more fragmentation of cellulose end terminals than in the longer treatments. These results are important because they show the impact of using repeated BaCel5 washes, which are not observed in single and longer uses.

The cotton samples without enzymatic treatment appeared mostly as smooth surfaces but some defects were observed (Fig. 7). Micrographs B, C and D in Fig. 7 show the physical changes of the cotton fibres after each treatment. Cotton treated several times showed an significant number of loose fibrils. However, BaCel5 action appears to hy- drolyse fibrils at the surface of the fibres, without penetration or damage of the interior of the fibres. In the case of longer treatments, similar numbers of created fibrils were observed in both cases, but fabric damage was also observed in the 48 - $\mathrm{h}$ samples. The similar results obtained for 200-min and $48-\mathrm{h}$ treatments may be due to the crystalline nature of cotton cellulose. Others [36, 37] have verified that monocomponent enzymes with long measurable enzyme activity do not yield any measurable reducing sugar products after a few hours of treatment. This particular enzyme has been shown to be able to yield sugar from fresh cotton surface with no mechanical agitation. Our enzyme was expected to have a similar stability since it was shown to remain active at least for 120 or $20 \mathrm{~min}$.

As the aim of this study was to analyse the effect of several BaCel5 treatments on cotton fibres, reproducing the household washing, no further analysis regarding the activity in longer treatments

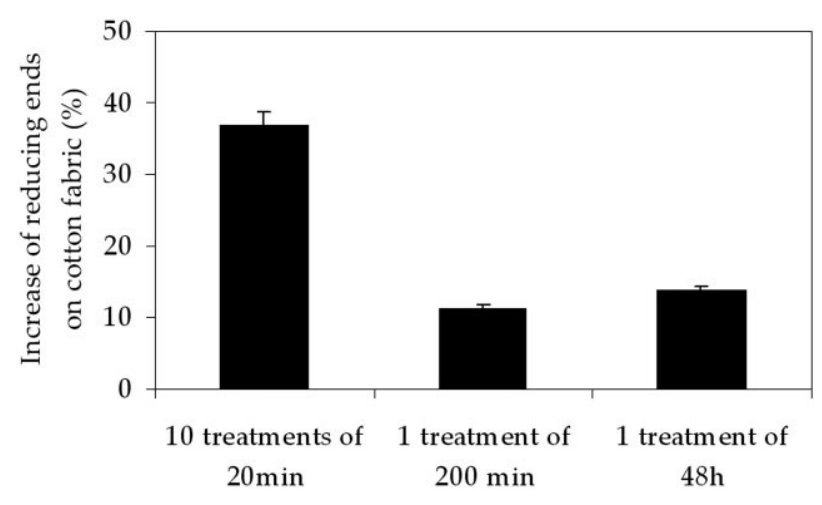

Figure 6. Percentages of reducing ends for indicated incubation periods ( $1 \mathrm{mg}$ protein $/ \mathrm{L} ; 40^{\circ} \mathrm{C} ; 125 \mathrm{rpm}$ ). Values represent the mean of three independent experiments and error bars the SD. 

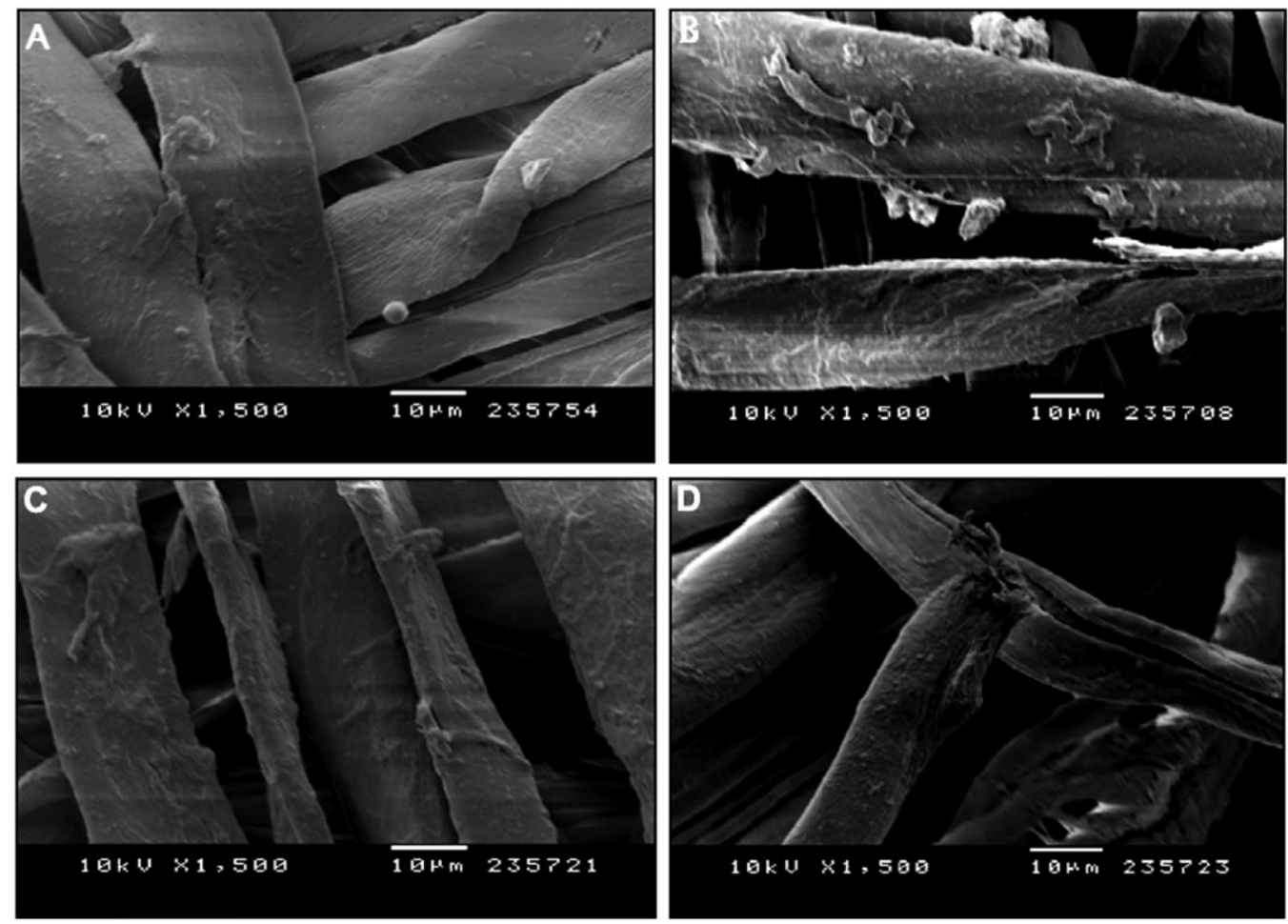

Figure 7. SEM photographs of cotton fabrics. (A) Control sample without enzymatic treatment; (B) ten treatments of about 20 min; (C) 200 -min and (D) 48 -h treatment $\left(1 \mathrm{mg}\right.$ protein $\left./ \mathrm{L} ; 40^{\circ} \mathrm{C} ; 125 \mathrm{rpm}\right)$.

were carried out. The defects may have resulted from a combined action of inter-fibre friction and mechanical agitation during the treatments.

The first step in enzymatic degradation of the cellulose microfibrils, leading to the formation of even thinner subfibrils, has been proposed by several authors; however, a deeper appreciation of the morphology and structure of cotton fibres is required from the cleaning standpoint $[21,23,39$, 42-52]. In the present studies, the enzymatic action of repeated treatments resulted in the production of short fibres on the cotton fibre. The SEM studies confirmed the short fibre formation on repeated enzymatic treatments. Although release of short fibres was observed within $20 \mathrm{~min}$, an increase of the accessible surface area was verified and was used to monitor the impact of the enzyme. The enzyme might preferentially attack new areas of the fibre, rather than continuing to release the microfibrils that had been cut in the previous washing cycles into the liquor bath. The short fibre formation was assumed to represent the reducing groups on the cotton surface. It is notable that surface modification occurred on repeated treatments and not in longer single treatments. This may be attributed to preferential hydrolysis of short fibres formed by endoglucanase action. Many researchers have as- signed the formation of short fibres to a property of endoglucanases [53].

\section{Concluding remarks}

Cotton fibres can be converted into microfibrillar material by the action of enzyme hydrolysis in short periods of time using an endoglucanase-cellulase system. The production of fibrillation on cotton fibre surface without any release of cellulosic material (reducing sugar generation) proves that $\mathrm{BaCel} 5$ tends to be an action of the first stage of cotton hydrolysis, using low concentrations of cellulase and short time treatments. Therefore, the use of BaCel5 helps to avoid fabric damage, thus enhancing fabric care benefits.

This work is funded by European Union funds through the Marie Curie Fellowships (MEST-CT2005-019885) from the Sixth Framework Programme (FP6).

N. L. and J. M. are paid employees of Procter \& Gamble. The other authors declare no conflict of interest. 


\section{References}

[1] Cowan, D., Industrial enzyme technology. Trends Biotechnol. 1996, 14, 177-178.

[2] Starace, C. A., Detergent enzymes - Past, present and future. J. American Oil Chem. Soc. 1983, 60, 1025-1027.

[3] Uhlig, H., Linsmaier-Bednar, E. M., Industrial enzymes and their applications, Wiley-IEEE 1998.

[4] Bhat, M. K., Cellulases and related enzymes in biotechnology. Biotechnol. Adv. 2000, 18, 355-383.

[5] Ferraz, A., Guerra, A., Mendonza, R., Masarin, F. et al., Technological advances and mechanistic basis for fungal biopulping. Enzyme Microb. Technol. 2008, 43, 178-185.

[6] Levy, I., Shoseyov, O., Cellulose-binding domains: Biotechnological applications. Biotechnol. Adv. 2002, 20, 191-213.

[7] Peacock, E. E., Characterization and simulation of waterdegraded archaeological textiles: a review. International Biodeterioration \& Biodegradation 1996, 35-37.

[8] Silva, C., Da, S., Silva, N., Matama, T. et al., Engineered Thermobifida fusca cutinase with increased activity on polyester substrates. Biotechnol. J. 2011, 6, 1230-1239.

[9] Guimaraes, C., Kim, S., Silva, C., Cavaco Paulo, A., In situ laccase assisted overdyeing of denim using flavonoids. Biotechnol. J. 2011, 6, 1272-1279.

[10] Bisaria, V. S., Ghose, T. K., Biodegradation of cellulosic materials: Substrates, microorganisms, enzymes and products. Enzyme Microb. Technol. 1981, 3, 90-103.

[11] Boisset, C., Chanzy, H., Schulein, M., Henrissat, B., An ultrastructural study of the interaction of a fungal endoglucanase from Humicola insolens with cotton fibre. Cellulose 1997, 4, 7-20.

[12] Hoshino, E., Chiwaki, M., Suzuki, A., Murata, M., Improvement of cotton cloth soil removal by inclusion of alkaline cellulase from Bacillus sp. KSM-635 in detergents. J. Surfactants Detergents 2000, 3, 317-326.

[13] Ito, S., Kobayashi, T., Ara, K., Ozaki, K. et al., Alkaline detergent enzymes from alkaliphiles: Enzymatic properties, genetics, and structures. Extremophiles 1998, 2, 185-190.

[14] Murata, M., Hoshino, E., Yokosuka, M., Suzuki, A., New detergent mechanism using cellulase revealed by change in physicochemical properties of cellulose. J. Am. Oil Chem. Soc. 1993, 70, 53-58.

[15] Otzen, D. E., Christiansen, L., Schulein, M., A comparative study of the unfolding of the endoglucanase Cel45 from $\mathrm{Hu}$ micola insolens in denaturant and surfactant. Protein Sci. 1999, 8, 1878-1887.

[16] Schulein, M., Protein engineering of cellulases. Biochim. Biophys. Acta 2000, 1543, 239-252.

[17] Shikata, S., Saeki, K., Okoshi, H., Yoshimatsu, T. et al., Alkaline cellulases for laundry detergents: Production by alkalophilic strains of Bacillus and some properties of the crude enzymes. Agric. Biol. Chem. 1990, 54, 91-96.

[18] Shirai, T., Ishida, H., Noda, J. i., Yamane, T. et al., Crystal structure of alkaline cellulase $\mathrm{K}$ : Insight into the alkaline adaptation of an industrial enzyme. J. Mol. Biol. 2001, 310, 1079-1087.

[19] Novak-Hofer, I., Siegenthaler, P. A., Two-dimensional separation of chloroplast membrane proteins by isoelectri focusing and electrophoresis in sodium dodecyl sulphate. Biochim. Biophy. Acta 1977, 468, 461-471.

[20] Boisset, C., Ptrequin, C., Chanzy, H., Henrissat, B., Schulein, M., Optimized mixtures of recombinant Humicola insolens cellulases for the biodegradation of crystalline cellulose. Biotechnol. Bioeng. 2000, 72, 339-345.
[21] Chanzy, H., Henrissat, B., Electron microscopy study of the enzymic hydrolysis of Valonia cellulose. Carbohydr. Polymer 1983, 3, 161-173.

[22] Din, N., Gilkes, N., Tekant, B., Miller jr, R. C. et al., Non-hydrolytic disruption of cellulose fibres by the binding domain of a bacterial cellulase. Biotechnology 1991, 9, 1096-1099.

[23] Percival Zhang, Y. H., Lynd, L. R., Towards an aggregated understanding of enzymatic hydrolysis of cellulose: Noncomplexed cellulase systems. Biotechnol. Bioeng. 2004, 88, 797824.

[24] Percival Zhang, Y. H., Lynd, L. R., A functionally based model for hydrolysis of cellulose by fungal cellulase. Biotechnol. Bioeng. 2006, 94, 888-898.

[25] Ito, S., Alkaline cellulases from alkaliphilic Bacillus: Enzymatic properties, genetics, and application to detergents. Extremophiles 1997, 1, 61-66.

[26] Ito, S., Shikata, S., Ozaki, K., Kawai, S. et al., Alkaline cellulase for laundry detergents: Production by Bacillus sp. KSM635 and enzymatic properties. Agric. Biol. Chem. 1989, 53, 1275-1281.

[27] Boraston, A. B., Kwan, E., Chiu, P., Warren, R. A., Kilburn, D. G., Recognition and hydrolysis of noncrystalline cellulose. J. Biol. Chem. 2003, 278, 6120-6127.

[28] Husum, T. L., Friis-Jensen, S., Wash the gray away. Ultimate whiteness with a new cellulase. SÖFW J. 2007, 133, 1-5.

[29] Shaw, A., Bott, R., Vonrhein, C., Bricogne, G. et al., A novel combination of two classic catalytic schemes. J. Mol. Biol. 2002, 320, 303-309.

[30] Suzuki, A., Susumi, I., Okamoto, K., Hoshino, E. et al., Detergent composition for clothing 1988, EP0271,004.

[31] Obendorf, S. K., Varanasi, A., Mejldal, R., Nielsen, V. S., Lipid distribution on cotton textiles in relation to washing with cellulase. J. Surfactants Detergents 2003, 6, 1-5.

[32] Boraston, A. B., Nurizzo, D., Notenboom, V., Ducros, V. et al., Differential oligosaccharide recognition by evolutionarilyrelated $\beta-1,4$ and $\beta-1,3$ glucan-binding modules. J. Mol. Biol. 2002, 319, 1143-1156.

[33] McLean, B. W., Boraston, A. B., Brouwer, D., Sanaie, N. et al., Carbohydrate-binding modules recognize fine substructures of cellulose. J. Biol. Chem. 2002, 277, 50245-50254.

[34] Fakin, D., Golob, V., Stana Kleinschek, K., Sorption properties of flax fibers depending on pretreatment processes and their environmental impact. Textile Res. J. 2006, 76, 448-454.

[35] Ribitsch, V., Stana-Kleinschek, K., Kreze, T., Strnad, S., The significance of surface charge and structure on the accessibility of cellulose fibres. Macromol. Mater. Eng. 2001, 286, 648-654.

[36] Cavaco-Paulo, A., Mechanism of cellulase action in textile processes. Carbohydr. Polymer 1998, 37, 273-277.

[37] Cavaco-Paulo, A., Almeida, L., Bishop, D., Effects of agitation and endoglucanase pretreatment on the hydrolysis of cotton fabrics by a total cellulase. Textile Res. J. 1996, 66, 287294.

[38] Hoshino, E., Kanda, T., Sasaki, Y., Nisizawa, K., Adsorption mode of exo- and endo-cellulases from Irpex lacteus (Polyporus tulipiferae) on cellulose with different crystallinities. J. Biochem. 1992, 111, 600-605.

[39] Hoshino, E., Sasaki, Y., Okazaki, M., Nisizawa, K., Kanda, T., Mode of action of exo- and endo-type cellulases from Irpex lacteus in the hydrolysis of cellulose with different crystallinities. J. Biochem. 1993, 114, 230-235.

[40] Maurer, K. H., Development of new cellulases, in: Van Ee, J. H., Misset, O., Baas, E. J. (Eds.), Enzymes in detergency, Marcel Dekker, New York 1997, pp. 177-177. 
[41] Grethlein, H. G., Effect of pore size distribution on the rate of enzymatic hydrolysis of cellulosic substrates. Biotechnology $1985,3,155-160$.

[42] Hoshino, E., Sasaki, Y., Mori, K., Okazaki, M. et al., Electron microscopic observation of cotton cellulose degradation by Exo- and Endo-type cellulases from Irpex lacteus. J. Biochem. 1993, 114, 236-245.

[43] Wang, L., Zhang, Y., Gao, P., Shi, D. et al., Changes in the structural properties and rate of hydrolysis of cotton fibers during extended enzymatic hydrolysis. Biotechnol. Bioeng. 2006, 93, 443-456.

[44] Calvimontes, A., Lant, N., Dutschk, V., Cooperative action of cellulase enzyme and carboxymethyl cellulose on cotton fabric cleanability from a topographical standpoint. J. Surfactants Detergents 2011, 14, 307-316.

[45] Gupta, R., Lee, Y.Y., Mechanism of cellulase reaction on pure cellulosic substrates. Biotechnol. Bioeng. 2009, 102, 15701581.

[46] Gusakov, A. V., Salanovich, T. N., Antonov, A. I., Ustinov, B. B. et al., Design of highly efficient cellulase mixtures for enzymatic hydrolysis of cellulose. Biotechnol. Bioeng. 2007, 97, 1028-1038.
[47] Levine, S. E., Fox, J. M., Blanch, H. W., Clark, D. S., A mechanistic model of the enzymatic hydrolysis of cellulose. Biotechnol. Bioeng. 2010, 107, 37-51.

[48] Linder, M., Salovuori, I., Ruohonen, L., Teeri, T. T., Characterization of a double cellulose-binding domain. Synergistic high affinity binding to crystalline cellulose. J. Biol. Chem. 1996, 271, 21268-21272.

[49] Linder, M., Teeri, T. T., The roles and function of cellulosebinding domains. J. Biotechnol. 1997, 57, 15-28.

[50] Liu, H., Fu, S., Zhu, J.Y., Li, H., Zhan, H., Visualization of enzymatic hydrolysis of cellulose using AFM phase imaging. Enzyme Microb. Technol. 2009, 45, 274-281.

[51] Schimper, C., Ibanescu, C., Bechtold, T., Effect of alkali pretreatment on hydrolysis of regenerated cellulose fibers (part 1: viscose) by cellulases. Cellulose 2009, 16, 1057-1068.

[52] Teeri, T. T., Crystalline cellulose degradation: new insight into the function of cellobiohydrolases. Trends Biotechnol. 1997, 15, 160-167.

[53] Halliwell, G., Riaz, M., The formation of short fibres from native cellulose by components of Trichoderma koningii cellulase. Biochem. J. 1970, 116, 35-42. 